\title{
Sexually Transmitted Illnesses in Masvingo Province, 2012-2015: A Secondary Data Analysis
}

\section{Noriah M. Hwami ${ }^{1}$, Tsitsi P. Juru ${ }^{*}$, Amadeus Shamu ${ }^{2}$, Gerald Shambira ${ }^{1}$, Notion Tafara Gombe1, Mufuta Tshimanga ${ }^{1}$}

${ }^{1} \mathrm{MPH}$ Programme, Department of Community Medicine, University of Zimbabwe, Harare, Zimbabwe

${ }^{2}$ Provincial Medical Directorate, Ministry of Health and Child Care, Masvingo, Zimbabwe

Email:noriapasi6@gmail.com, ${ }^{\star}$ tjuru@zimfetp.net, amashamu@yahoo.com,gshambira@yahoo.com,ntgombent@zimfetp.net,

mufutatshimanga@gmail.com

How to cite this paper: Hwami, N.M., Juru, T.P., Shamu, A., Shambira, G., Gombe, N.T. and Tshimanga, M. (2017) Sexually Transmitted Illnesses in Masvingo Province, 20122015: A Secondary Data Analysis. Open Journal of Epidemiology, 7, 59-68.

https://doi.org/10.4236/ojepi.2017.71006

Received: December 16, 2016

Accepted: February 12, 2017

Published: February 15, 2017

Copyright (c) 2017 by authors and Scientific Research Publishing Inc. This work is licensed under the Creative Commons Attribution International License (CC BY 4.0).

http://creativecommons.org/licenses/by/4.0/

\begin{abstract}
Background: Masvingo province is among the top three provinces with high Genital Ulcer Disease incidence rates in Zimbabwe. There has been no documented evidence to establish the burden and epidemiology of STIs in Masvingo province. We analysed these data to describe trends in STIs from 20122015. Methods: A retrospective records review of Masvingo STI data set was conducted. We assessed trends in STIs from 2012-2015. Microsoft Excel 2010 software was used to generate bar and linear graphs. Epi info $7^{\text {th }}$ was used to calculate Chi-square for trends and p values. Results: Most affected age group was 25 - 49 years (incidence rate of 73.9 cases per 1000). The 50 and above age group had a higher incidence rate than the $10-24$ year age group $(27.5$ compared to 15.5 cases per 1000). STI incidence was higher in females ( 31.9 cases per 1000) than in males (20.6 cases per 1000). The most prevalent STIs were vaginal discharge 48,972 (30.7\%) and other forms of STIs 35,777 (22.3\%). Masvingo district recorded the highest STI incidence rate (34.1 cases per 1000). There was a decline in HIV testing rates from $36(100 \%)$ to 12,190 $(64.4 \%)(\mathrm{p}<0.001)$ from 2012-2015. Conclusion: There was a general decline in the STI trends for all age groups. Age group most affected by STIs was the 25 - 49 years with females being more affected. HIV testing services among STI clients declined. We recommend advocacy on safe sexual practices and further research to identify reasons for low uptake of HIV testing services among STI clients.
\end{abstract}

\section{Keywords}

Sexually Transmitted Illnesses, Incidence, Masvingo, Zimbabwe 


\section{Background}

Sexually Transmitted Infections (STIs) cause considerable mortality and morbidity in both adults and new-borns and expedite the transmission of Human Immunodeficiency Virus (HIV) infection [1]. They are spread principally by sexual contact, including vaginal, anal and oral sex. STIs can also be spread through non-sexual means such as via blood or blood products and from mother to child during pregnancy and child birth [1]. Marginalized populations with highest rates for STIs like sex workers, drug users, men who have sex with men and adolescents have limited access to adequate health care services [2].

An estimated half a billion new curable STIs occur worldwide each year. Syphilis, gonorrhea and chlamydia remain major causes of disability and death despite being curable with antibiotics [3]. The estimated annual incidence of non-HIV STIs has increased by nearly 50\% during the period 1995-2008. The growth in STIs has been aggravated by lack of accurate, inexpensive diagnostic tests and absence of surveillance and reporting systems in the majority of countries among other factors [1]. The largest proportion of STIs occur in developing nations, led by South and Southeast Asia, followed by sub-Saharan Africa, Latin America, and the Caribbean [4].

As outlined in the global strategy for the prevention and control of sexually transmitted Infections 2006-2015, effective STI control relies on reliable, routine reporting from STI surveillance systems [3]. Strong surveillance systems enable national health authorities, policy-makers, and STI program managers to effectively monitor epidemic trends, identify severe or emerging epidemic outbreaks and strategically direct the investment of resources where they are needed most [3].

In Zimbabwe, prior to 1980 STI data were provided mainly from urban hospitals while data from rural treatment centers were not submitted for compilation [5]. This type of disease surveillance was not representative of the national picture, and did not provide the basis for effective and systematic action [5]. The system was not well coordinated and steps were taken to correct the anomaly [5]. The existing system was reviewed in 1984 in order to improve the collection, analysis, dissemination and the use of health information. The objective was to ensure that the relevant health data needed for planning, monitoring and evaluation and research on STIs was readily available at all levels and at all times [5]. By 1987 National Health Information Service (NHIS) was put in place to provide health workers, public health planners and managers with surveillance and operational data throughout the country [6].

The sexually transmitted data base is a consolidated electronic form which includes all the sexually transmitted illnesses that are reported at health facilities in Masvingo province. The data set was set up in 2012 to provide health data for monitoring STI trends, identifying emerging outbreaks, directing investment of resources in prevention, treatment care and control and assessing the effectiveness of these efforts. Data are captured daily in health facilities using paper based tally forms known as T3 forms and a monthly summary is made on another pa- 
per based tally form known as T5 form. The T5 form records a total of four STI syndromes by age group and sex. These include urethral discharge, vaginal discharge, genital ulcer disease, Pelvic Inflammatory Disease (PID) and opthalmia neonatorum.

STI/HIV integration data are captured in STI registers at health facility level. The indicators captured include number of STI clients who receive HIV counselling, number of STI clients tested for HIV, number of clients who test HIV positive and number of STI contacts treated. Data are consolidated on PMTCT monthly return forms at the end of the month. The health facilities send the previous month $\mathrm{T} 5$ forms and monthly return forms to the district by the $7^{\text {th }}$ of the following month. The district aggregates and validates data from health centers and enters the data onto the Demographic Health Information System (DHIS 2) system which automatically uploads to the National Health Information system by the $27^{\text {th }}$ of the month.

Genital Ulcer disease trends (GUD) are a good indicator of the performance of STI/HIV control efforts. A rising GUD trend strongly suggests that sexual transmission in unprotected sex is increasing in a population [7]. Masvingo Province is among the three provinces in the country with high genital ulcer incidence rates (July-September 2016). This is disturbing as Genital Ulcer Disease increases HIV transmission probabilities in unprotected sex by three fold [7]. Statistics from DHIS 2 also indicate that the number of new STI cases from $4^{\text {th }}$ quarter of 2015 to $1^{\text {st }}$ quarter of 2016 in the province rose by 8.3\% (9495 to $10,355)$.

Data on sexually transmitted illnesses have been collected routinely for a long period in the province but it has not been analyzed to establish the burden of STIs and their epidemiology and impact on health service provision. It is important to identify the most prevalent STIs in the province. This information can be used in allocation of STI control resources and in assessing the adequacy of overall STI/HIV prevention efforts.

\section{Methods}

We conducted a retrospective records review of Masvingo STI data from 20122015 (see Table 1). Data were extracted from the Demographic Health Information System (DHIS 2) and imported into Microsoft excel 2010 to generate bar and linear graphs. We used Epi info $7^{\text {tox }}$ to calculate Chi-square for trends and $\mathrm{p}$ values. We assessed STI trends by age group and sex. The four STI syndromes are Urethral/Vaginal discharge, Genital Ulcer Disease (GUD), Opthalmia neonatorum and Pelvic Inflammatory Disease (PID) [8]. Repeat STI visits and other forms of STIs were also analysed. STI/HIV integration variables analysed include number of STI clients tested for HIV, number of STI clients who tested HIV positive, and number of STI contacts who received treatment. Data set was checked for completeness and consistencyand there was no missing data. Permission to carry out the study was obtained from Masvingo Provincial Medical Directorate and Health Studies Office (HSO). Ethical clearance was sought from 
the Institutional Review Board for Masvingo Provincial Directorate. Confidentiality was assured and maintained during and after the study by not linking STI data to individuals and sharing data with relevant authorities only.

\section{Results}

The study demonstrated that most affected age groups were the 25 - 49 years and the 50+ age group (Figure 1). There was a general decline in the STI trends for all age groups from 2012 to 2015 in Masvingo Province. Overall, there was a significant decline in STI incidence for both males (Chi-square $=223$ and $\mathrm{p}=$ 0.0321 ) and females (Chi-square $=5672$ and $\mathrm{p}=0.0234$ ) for the period 2012 to 2015. Females had a significantly higher incidence of STIs compared to males from 2012-2015 (Figure 2). The most prevalent STI in the province from 2012-2015 was vaginal discharge with 48,972 (30.7\%) followed by other forms of STIs with $35,777(22.3 \%)$. The least prevalent STI was Opthalmia Neonatorum with 578 (0.4\%) (Figure 3).

Masvingo province had the highest STI incidence whilst Mwenezi district had the lowest (Figure 4). There was a decline in repeat visits from 2013 to 2015 (Chi-square $=324$ and $\mathrm{p}=0.001$ ). Chivi district recorded the highest number of repeat visits over the four year period. Mwenezi district recorded the lowest

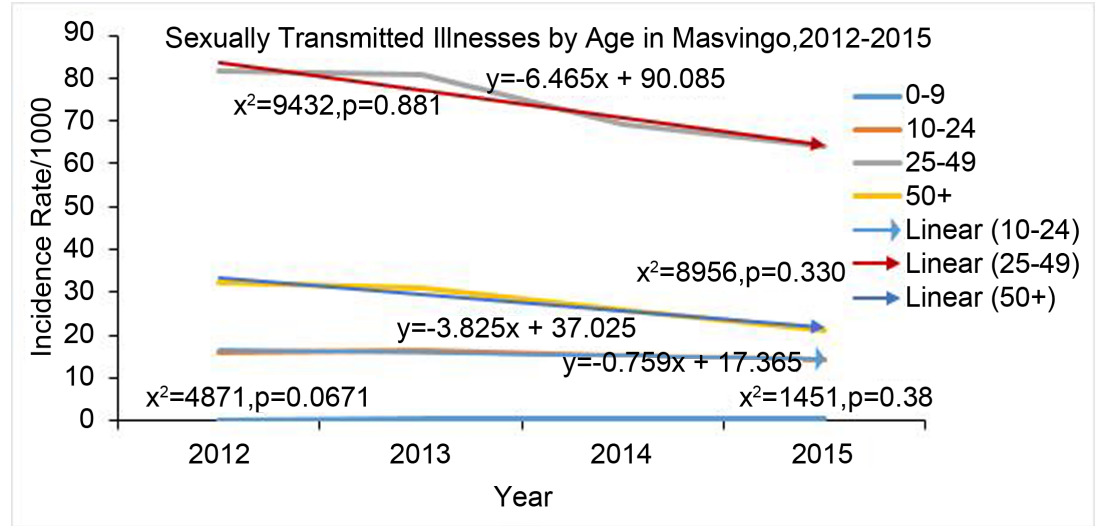

Figure 1. Trends in sexually transmitted illnesses by age, Masvingo, 2012-2015.

Table 1. Variables analyzed in the study, Masvingo, 2012-2015.

\begin{tabular}{|c|c|c|}
\hline Variable & Age group in years & Sex \\
\hline Urethral/vaginal discharge & $0-9,10-24,25-49,50+$ & Male and females \\
\hline Pelvic inflammatory disease & $0-9,10-24,25-49,50+$ & Females only \\
\hline Genital ulcer disease & $0-9,10-24,25-49,50+$ & Males and females \\
\hline Opthalmia neonatorum & $0-9$ & Males and females \\
\hline Other forms of STIs & $0-9,10-24,25-49,50+$ & Males and females \\
\hline Repeat visits & $0-9,10-24,25-49,50+$ & Males and females \\
\hline Number of STI clients counselled for HIV & $0-4,5-9,10-14,15-19,20-24,25-49,50+$ & Males and females \\
\hline Number of STI clients tested for HIV & $0-4,5-9,10-14,15-19,20-24,25-49,50+$ & Males and females \\
\hline Number of STI clients tested HIV positive & $0-4,5-9,10-14,15-19,20-24,25-49,50+$ & Males and females \\
\hline Number of STI contacts treated & $10-14,15-19,20-24,25-49,50+$ & Males and females \\
\hline
\end{tabular}




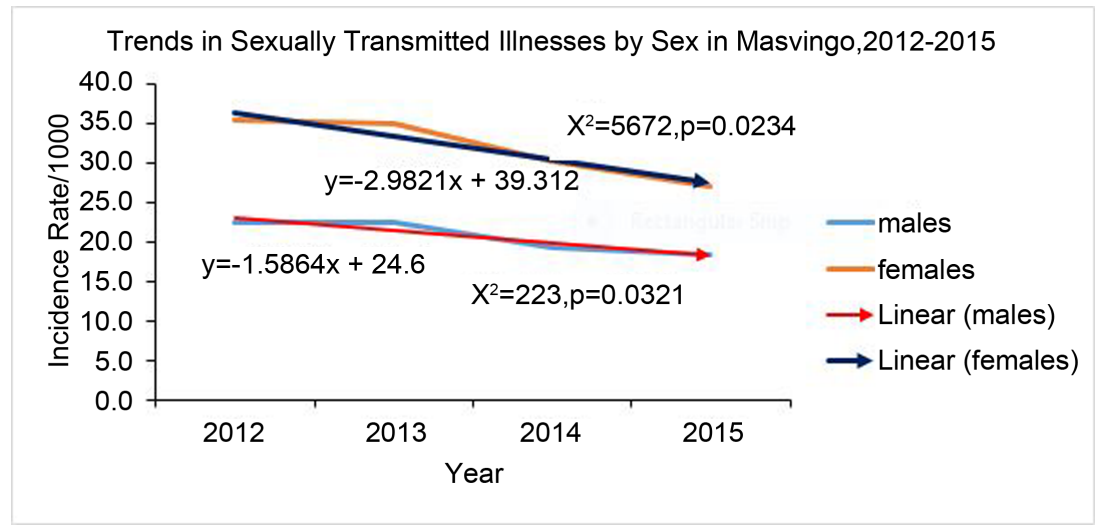

Figure 2. Trends in sexually transmitted illnesses by sex, Masvingo, 2012-2015.

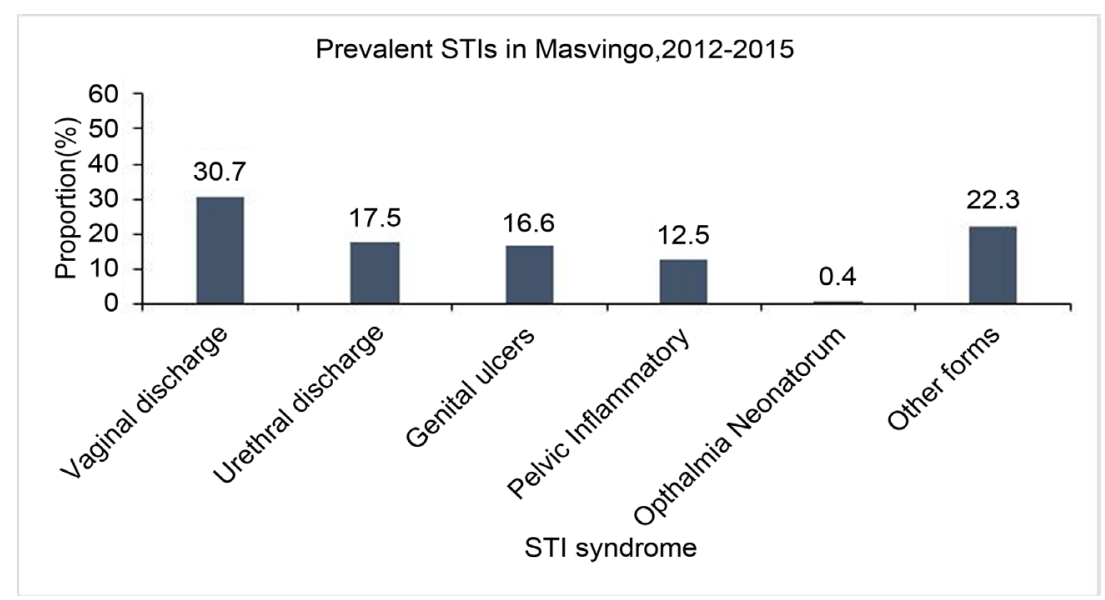

Figure 3. Prevalent sexually transmitted illnesses syndromes, Masvingo, 2012-2015.

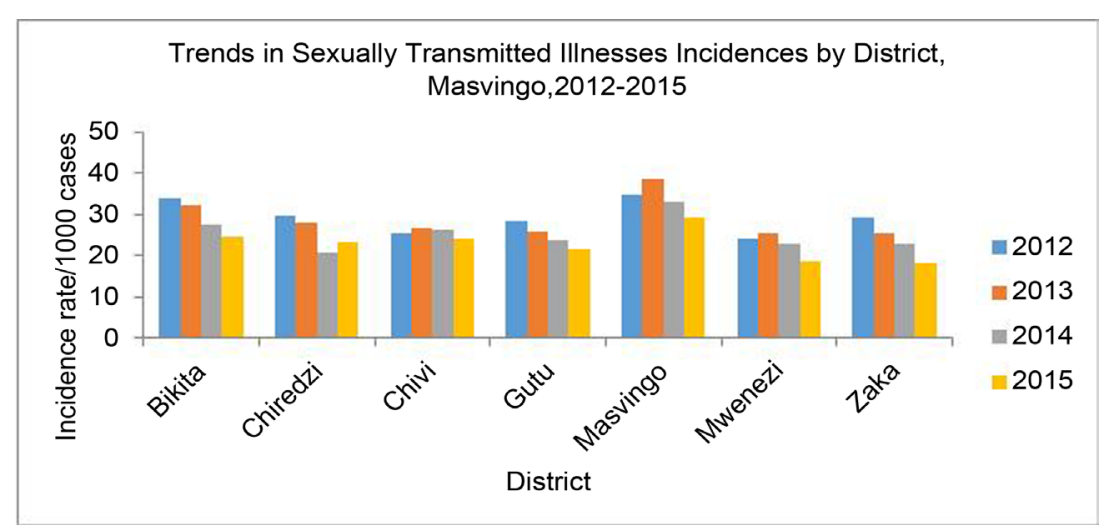

Figure 4. Sexually transmitted illnesses incidences by district in Masvingo, 2012-2015.

numbers of repeat STI visits. A decline in HIV testing uptake from 36 (100\%) in 2012 to $12,190(64.4 \%)$ in 2015 was recorded in Masvingo province (Chi-square = 441 and $\mathrm{p}<0.001$ ) (Figure 5). There was an increase in HIV positivity rates among STI clients who were tested for HIV from 3 (8.3\%) in 2012 to 1378 $(11.3 \%)$ in 2015 (Chi-square $=545, \mathrm{p}=0.007)$. There was also an insignificant increase in the number of STI contacts who received treatment in Masvingo province from 2012-2015 (chi-square $=112$ and $\mathrm{p}=0.213$ ). 
Trends in HIV Testing Uptake among Sexually Transmitted IIInesses Clients, Masvingo, 2012-2015

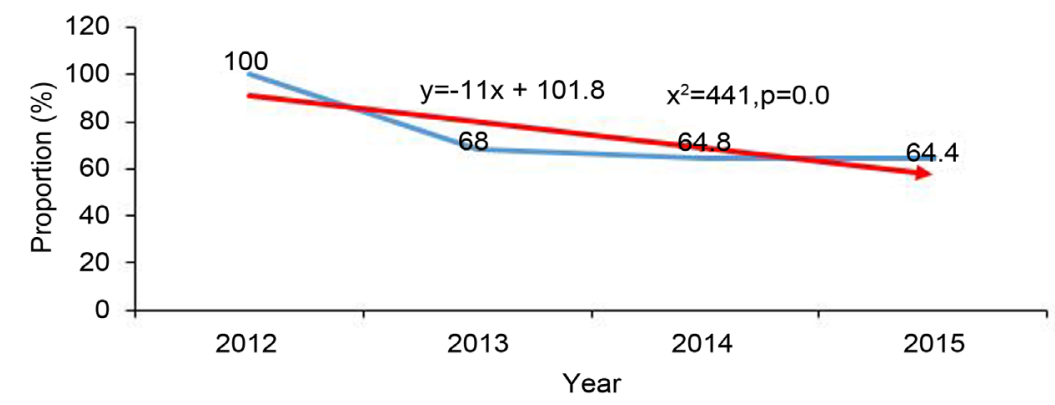

Figure 5. Trends in HIV testing uptake rates among sexually transmitted illnesses clients in Masvingo, 2012-2015.

\section{Discussion}

The burden of sexually transmitted illnesses in Masvingo province has marginally declined during the four-year period. The decline in the incidence of STIs may be attributed to behavior change amongst the sexually active age group. Organizations are actively involved in STI awareness campaigns in Masvingo province in all the districts targeting HIV hot spots, and places of gatherings. The road shows teach on STI prevention and control strategies using local public actors. STI awareness materials and condoms are distributed during the shows. A total of 145,483 students were taught on HIV/AIDS through the Youth in school Action AIDS clubs in 2015.

Masvingo district recorded the highest incidence of STIs whilst Mwenezi district recorded least incidence in the four year period under review. This could be due to the fact that Masvingo district has referral hospitals like Masvingo provincial hospital and Mogenster hospital which have large catchment areas. Residents of rural areas in other districts in the province may have less access to STI care and treatment than their urban counterparts in Masvingo district which includes Masvingo town. Chiredzi district recorded third highest incidence rates in 2013 despite it being a boarder district.

A hot spot analysis report by the Ministry of Health and Child care, (2015) reported that risk factors for contracting HIV are generally high in provinces with main border entry points [9]. A study by Matovu and Ssebadduka, (2012) in Uganda reported that female sex workers and truckers engage in high risk sexual behaviors along major transport corridors [10]. Consistent condom use was low in the study, with $21 \%$ of the truckers and $45 \%$ of the female sex workers reporting consistent condom use [10]. Similar findings were reported by Dude et al., (2009) in India who reported that most truck drivers in South India engage in risky sexual behaviors [11]. In the study, $11.6 \%$ of the drivers reported having visited a sex worker in the past six months and $15.3 \%$ reported having multiple sexual partners in the past year [11]. Masvingo highway is a major transport route used by haulage truckers linking Zimbabwe and South Africa through the Beitbridge border. 
The most affected age group was the 25 - 49 year age group. This is the sexually active age group and hence at higher risk of sexually transmitted illnesses. These findings are similar to a study done in India by Goel and Goel, (2012) who reported that $39.7 \%$ of STI cases was in the age group of $21-30$ years [12]. The $50+$ year group has a higher incidence rate of sexually transmitted illnesses compared to the 10 - 24 year age group. This could be a result of intergenerational relationships between the elderly and the young sexually active age group. A high level of asymmetry in sexual networking was reported in Zimbabwe by Decosas and Padigan, (2002) [13]. Young men have a highly diversified network of sexual partners that involves a small proportion of young women [13].

Women were more affected by STIs than men. This might be a true picture of the situation or can be a result of good health care seeking behavior of women as compared to men. A study by Takarinda et al., (2011) in Zimbabwe reported that antenatal care visits and other maternal health services are an important means of accessing health services amongst women [14]. Pregnant women are tested for syphilis during their first antenatal booking at twelve weeks in Zimbabwe. Sague et al., (2014) reported that females are at a higher risk of contracting HIV and other sexually transmitted infections than their male counterparts [15]. This is because of their biological make up, hormonal effects, and changes in the protective female genital tract flora [15]. Ramjee and Daniels, (2013) added that the reason why females are at risk of HIV than men was because of economic issues like engaging in commercial sex work [16].

The most prevalent STI syndromes for the four year period were vaginal discharge (30.7\%), other forms of STIs (22.3\%) and genital ulcer disease (16.6\%). Similar findings were found by Goel and Goel, (2012) who reported the most prevalent STI syndromes as vaginal syndrome (43.7\%) and genital ulcer (30.6\%) [12]. A study by Decosas and Padian, (2002) done in Zimbabwe reported that data on vaginal discharge syndromes and other forms of STIs are difficult to interpret [13]. This is because causes of bacterial vaginosis may include the use of vaginal drying agents, douching, or other inappropriate hygiene practices [13].

Opthalmia Neonatorum had the lowest incidence compared to other STI syndromes but its existence is an indication of congenital infection in the population. World Health Organization in 2007 launched a global initiative to eliminate congenital syphilis as a public health problem [6]. Strengthening of simple and cost effective STI prevention programs such as syphilis screening during pregnancy can go a long way in preventing congenital STIs [7].

There was a significant decline in HIV testing and counselling services in the four year period from $100 \%$ to $64.4 \%$. This could be a result of some data not being reported as the data base was established in 2012 or it could be a true picture of STI clients not accessing HIV testing services. Greater effort has to be made to strengthen HIV Testing Services in STI clinics if Zimbabwe is to realize UNAIDS's vision of zero new HIV infections, zero discrimination, and zero AIDS-related deaths by the year 2020 [17]. Provider Initiated Testing and Counselling (PITC) in STI clinics can increase the number of STI clients who access HIV testing services. 
Our study had a limitation that we could not verify whether the information in the provincial data base was a true reflection of all reported STI cases in different health facilities as this would require more resources.

\section{Conclusion}

There was a general decline in the STI trends for all age groups from 2012 to 2015 in Masvingo Province. The age group that was most affected by STIs in the province was the 25 to 49 year age group. Females were more affected by STIs than their male counterparts. Districts with urban and peri-urban settlements such as Masvingo district were the worst affected by STIs in the province. The most prevalent STI in the province was vaginal discharge. Chivi district recorded the highest number of repeat visits over the four-year period. HIV testing services uptake among STI clients are also declining in the province. We recommend advocacy on safe sexual practices among the $25-49$ and 50+ year age groups and uptake of HIV testing services among STI clients in Masvingo province. Further research is required to identify reasons for low uptake of HIV testing services among STI clients in Masvingo province.

\section{What Is Already Known on This Topic?}

Females are more affected by STIs than males. The $25-49$ year age has the highest incidence of STIs compared to other age groups.

\section{What This Study Adds}

HIV testing services uptake among STI clients declined in Masvingo, 2012-2015. The 50+ age group had a higher STI incidence compared to the 10 - 24 year age group in Masvingo, 2012-2015.

\section{Competing Interests}

The authors declare no competing interests.

\section{Funding}

The study was funded by Centres for Disease control and prevention (CDC).

\section{Authors' Contributions}

$\mathrm{NMH}, \mathrm{AS}$ : conception and design of study, acquisition of data, analysis and/or interpretation of data and drafting the manuscript. TJ: conception and design of study, acquisition of data, analysis and/or interpretation of data and reviewing several drafts of the manuscript for important intellectual content. GS, NTG, MT: conception and design of study and critically reviewing the manuscript for important intellectual content. All authors read and approved the final manuscript for publication.

\section{References}

[1] Ortayli, N., Ringheim, K., Collins, L. and Sladden, T. (2014) Sexually Transmitted 
Infections: Challenges since the 1994 International Conference on Population and Development (ICPD). Contraception, 90, S22-S31.

https://doi.org/10.1016/j.contraception.2014.06.024

[2] WHO (2016) Sexually Transmitted Infections. Fact Sheet No. 110. http://www.who.int/mediacentre/factsheets/fs110/en/

[3] World Health Organization (2013) Report on Global Sexually Transmitted Infection Surveillance. World Health Organization, Geneva.

[4] World Health Organization (2001) Global Prevalence and Incidence of Curable STIs. World Health Organization, Geneva.

[5] Ministry of Health and Child Welfare (2003) Zimbabwe National Health Surveillance System. (NHSS) T5, 17-28.

[6] Ministry of Health and Child Welfare (2007) Management of STI and RTI in Zimbabwe: A Guide to Essential Practice. 61-946.

[7] Freeman, E.E., Weiss, H.A., Glynn, J.R., Cross, P.L., Whitworth, J.A. and Hayes, R.J. (2006) Herpes Simplex Virus 2 Infection Increases HIV Acquisition in Men and Women: Systematic Review and Meta-Analysis of Longitudinal Analysis. AIDS, 20, 73-83. http://www.ncbi.nlm.nih.gov/pubmed/16327322 https://doi.org/10.1097/01.aids.0000198081.09337.a7

[8] Ministry of Health and Child Care, Harare, Zimbabwe (2016) DHIS 2. https://196.27.127.61/nhis/dhis-web-pivot/index.html

[9] Ministry of Health and Child Care (2015) Smart Investment to End HIV AIDS in Zimbabwe Based on Hotspot Analysis and Report by United Nations World Food Programme, Zimbabwe. https://doi.org/10.4103/0253-7184.102137

[10] Matovu, J. and Ssebadduka, B. (2012) Sexual Risk Behaviours, Condom Use and Sexually Transmitted Infection Treatment-Seeking Behaviours among Female Sex Workers and Truck Drivers in Uganda. International Journal of STD \& AIDS, 23, 267-273. https://doi.org/10.1258/ijsa.2011.011313

[11] Dude, A., Oruganti, G., Kumar, V., Mayer, K.H., Yeldandi, V. and Schneider, J.A. (2009) HIV Infection, Genital Symptoms and Sexual Risk Behavior among Indian Truck Drivers from a Large Transportation Company in South India. Journal of Global Infectious Diseases, 1, 21-28. https://doi.org/10.4103/0974-777X.52977

[12] Goel, S.S. and Goel, S.S. (2012) Study of Syndromic Management Approach in the Management of Sexually Transmitted Diseases in Rural Population. Indian Journal of Sexually Transmitted Diseases, 33, 146-147. https://doi.org/10.4103/0253-7184.102137

[13] Decosas, J. and Padian, N. (2002) The Profile and Context of the Epidemics of Sexually Transmitted Infections including HIV in Zimbabwe. Sexually Transmitted Infections, 78, i40-i46. https://doi.org/10.1136/sti.78.suppl_1.i40

[14] Takarinda, K.C., Madyira, L.K., Mhangara, M., Makaza, V., Maphosa-Mutsaka Rusakaniko, S., et al. (2016) Factors Associated with Ever Being HIV Tested in Zimbabwe: An Extended Analysis of the Zimbabwe Demographic and Health Survey (2010-2011). PLoS ONE, 11, e0147828. https://doi.org/10.1371/journal.pone.0147828

[15] Sague, C.B., Black, C., Morse, S.A. and Schmid, G. (2014) Women and Children First: The Impact of Sexually Transmitted Infections on Maternal and Child Health. Journal of Sexually Transmitted Diseases, 2014, Article ID: 671085.

[16] Ramjee, G. and Daniels, B. (2013) Women and HIV in Sub-Saharan Africa. AIDS Research and Therapy, 10, 30.

https://www.researchgate.net/publication/259315895_Women_and_HIV_in_sub-Sa 
haran_Africa

https://doi.org/10.1186/1742-6405-10-30

[17] Joint United Nations Programme for HIV/AIDS 90-90-90 (2014) An Ambitious Treatment Target to Help End the AIDS Epidemic. Joint United Nations Programme for HIV/AIDS, Geneva.

http://www.unaids.org/sites/default/files/media_asset/90-90-90_en_0.pdf

\section{Scientific Research Publishing}

Submit or recommend next manuscript to SCIRP and we will provide best service for you:

Accepting pre-submission inquiries through Email, Facebook, LinkedIn, Twitter, etc. A wide selection of journals (inclusive of 9 subjects, more than 200 journals)

Providing 24-hour high-quality service

User-friendly online submission system

Fair and swift peer-review system

Efficient typesetting and proofreading procedure

Display of the result of downloads and visits, as well as the number of cited articles

Maximum dissemination of your research work

Submit your manuscript at: http://papersubmission.scirp.org/

Or contact ojepi@scirp.org 